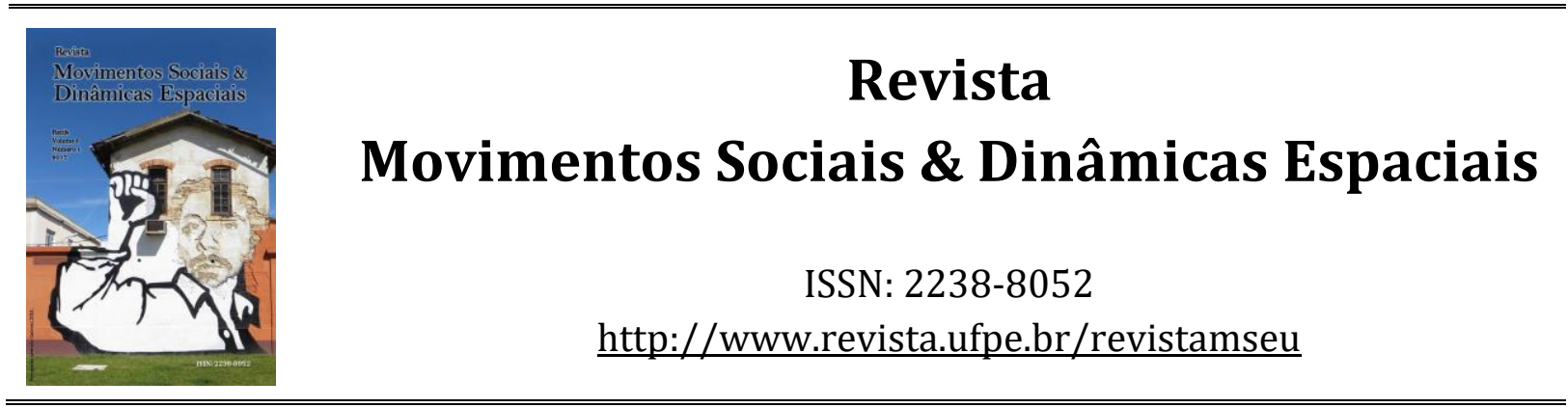

Ensaio recebido em 28/04/2017 e aceito em 14/07/2017.

\title{
ENSINO DE GEOGRAFIA: UM ENSAIO SOBRE SEUS DESAFIOS
}

GEOGRAPHY TEACHING: AN ESSAY ABOUT ITS CHALLENGES

Otávio Augusto Alves dos SANTOS1

\begin{abstract}
RESUMO
O objetivo deste ensaio é o de refletir sobre o ensino de Geografia, realizando um breve apanhado dos seus atuais desafios. Para tanto, recorre-se a um breve levantamento bibliográfico, onde se pontua a atualidade do pensamento geográfico, as tendências pedagógicas para a área de Geografia neste século XXI e a necessidade de se adequar um novo olhar geográfico e um novo modelo de ensino nas escolas.
\end{abstract}

Palavras-chaves: Ensino de Geografia; Globalização; Metodologia.

\begin{abstract}
The objective of this paper is to reflect on the teaching of Geography, making a little survey of its current challenges. For this we did a brief bibliographic survey, where the current geographic thought, the pedagogical tendencies for the area of Geography in this XXI century and the need to adapt a new geographical view and a new model of teaching in the schools.
\end{abstract}

Keywords: Geography Teaching; Globalization; Methodology.

\section{O NOVO OLHAR GEOGRÁFICO SOBRE O MUNDO}

Surgida sob a perspectiva de possibilitar um conhecimento sintético do espaço, a Geografia sempre foi uma ciência ambiciosa, obstinada a oferecer uma visão do todo global. Uma de suas primeiras acepções foi a de uma ciência voltada a descrever sinteticamente as paisagens, uma teoria sobre o mundo. Por isso é que Ritter, Humboldt e La Blache falavam de uma unidade da Terra. Entretanto, essa ciência alicerçou sua base científica no paradigma moderno

\footnotetext{
${ }^{1}$ Consultor Educacional da FTD Educação. Doutorando em Desenvolvimento Urbano pela UFPE. E-mail: otavioaas@gmail.com.
} 
cartesiano, em que o todo é fragmentado em diversas especializações. Assim é que surgiram as divisões Físico versus Humano, ou Geral versus Regional. Entre os geógrafos modernos foi minguando cada vez mais o propósito de compreender o todo e, em vez disso, surgiram as inúmeras geografias (urbana, rural, política, econômica, física etc.), cada qual desenvolvendo-se com base na relação com outras disciplinas.

A razão fragmentária, portanto, minou as possibilidades de conhecimento do mundo, ao passo que tornou a Geografia uma disciplina dilacerada, sem princípios científicos e categorias próprias, fortemente ameaçada. Milton Santos $(2004,2014)$, caracteriza com esmero as ameaças internas dessa ciência, mostrando que seu processo de renovação crítica correspondeu, antes de qualquer coisa, a busca por um fundamento de cientificidade. Desde essa renovação, portanto, os geógrafos vêm discutindo a história e os fundamentos epistemológicos dessa disciplina, revisando seus objetivos e metodologias. Vem daí, inclusive, uma renovada busca pela apreensão do todo, impulsionada pelas transformações político-econômicas do capitalismo tardio e por um certa "redescoberta da natureza".

Esse ressurgimento da busca pela apreensão do todo global, por sua vez, tem restaurado a importância da Geografia frente à sociedade e às demais ciências, algo que pode ser constatado através do interesse crescente da população pelo temário geográfico e pela atratividade e aproximação da Geografia em relação a outras disciplinas, tais como o urbanismo, a sociologia, a economia e a ciência política. Há, neste sentido, três fatores históricos que tem credenciado a Geografia na interpretação do mundo, quais sejam: a nova divisão internacional do trabalho; as estratégias geográficas de acumulação do capital; e a crise ambiental contemporânea. Esses fatores, por fim, constituem alguns dos aspectos mais notáveis da etapa mais recente do processo de mundialização do capital, também chamada de Globalização.

Do ponto de vista do trabalho, uma nova divisão internacional vem se constituído desde a segunda metade do século XX com a reestruturação produtiva e a expansão das grandes empresas multinacionais, ocasionando a industrialização dos países "subdesenvolvidos". Essa industrialização periférica é notadamente desigual, posto que as empresas que se direcionam para os países subdesenvolvidos são geralmente as mais degradantes do ponto de vista ambiental e que operam com patamares mais baixos de tecnologia. Em geral, tais empresas se deslocam geograficamente em busca de vantagens locacionais, como mão-de-obra barata e benefícios fiscais. Essa translocalização das empresas pelo globo, internacionalizando a produção, é responsável pela criação de um "sistema-mundo" (WALLERSTEIN, 1974) cuja compreensão de sua natureza econômica e sociológica exige diferentes conhecimentos geográficos.

O capital, por sua vez, possui uma estratégia geográfica. Ele se expande pelo globo desde sua irrupção, sendo essa uma das formas através das quais supera suas crises cíclicas. Baseado 
em Marx, Harvey (2006) afirma que o capitalismo está fadado a entrar em crise de sobreacumulação, de tempos em tempo. Tais crises, por sua vez, são superadas pela expansão geográfica em busca de novos mercados ou pela reconstrução (desvalorização-revalorização) de velhos espaços, processo esse que demanda uma grande quantidade de recursos, ao passo que inaugura novos patamares de acumulação. Neste sentido, o capital está sempre percorrendo novos lugares, constituindo uma geografia da valorização capitalista dos espaços. Quando isso não é possível, o capital projeta possibilidades (nem sempre garantidas) de acumulação futura pela via do mercado financeiro.

Esse processo de valorização aparentemente sem fim encontra, nos dias de hoje, os limites impostos pela natureza. As catástrofes naturais, o aquecimento global e os conflitos socioambientais põem na ordem do dia a questão ambiental, tomada enquanto problema mundial. Vista como uma externalidade passiva pelo racionalismo moderno, a natureza hoje demonstra seus imperativos. A crise ambiental contemporânea tem exigido das sociedades uma nova concepção de mundo e de desenvolvimento, questionando mesmo o progresso tecnológico e a produção de riquezas. Além disso, o caráter global dos problemas ambientais vem demonstrando que é necessária uma visão mais totalizante da natureza, que permita também vislumbrar a conflituosa relação estabelecida pelo homem.

Esses fatores históricos clamam por uma interpretação geográfica, que seja capaz de expor uma compreensão de mundo a partir de uma perspectiva crítica e com base em categorias pertinentes. Em resumidas contas, esses três fatores constituintes da Globalização não tem só restituído a importância e o papel da Geografia na interpretação do mundo atual, como também tem exigido dessa disciplina a necessidade de se lançar um novo olhar sobre esse mundo. Como diria Santos (2014), a universalização das técnicas trazida pelo próprio processo de mundialização do capital tornou possível o uso de categorias da Geografia, como o espaço, restabelecendo a importância desta disciplina ameaçada. Mas o olhar do geógrafo sobre esse mundo não deve ser o mesmo que o de cem ou cinquenta anos atrás. 0 mundo atual exige uma nova postura do geógrafo e do professor de Geografia.

Neste sentido, esses profissionais não podem mais observar o mundo como se ele estivesse parado, uma vez que as mudanças hoje são cada vez mais vorazes. Conforme afirma Moreira (2011), quando o geógrafo observava o mundo até a metade do século XX, constatava a paisagem de uma história humana que mal se transformava no transcurso dos anos. Ele via, portanto, as mudanças agindo lentamente sobre o espaço e, por isso, fazia-se largo uso de categorias como Região. A Geografia era sinônimo de regionalização. Vem dessa época, inclusive, a concepção segundo a qual o objetivo precípuo dessa disciplina seria regionalizar e estabelecer as diferenças entre as regiões por meio da comparação. Vale lembrar que, até a década de 1950, ainda não havia se constituído vigorosamente os sistemas de transporte e comunicação que se 
dispõe hoje, muito menos as redes de telefonia e internet que tornaram o espaço cada vez mais móvel e integrado. Vivia-se o tempo do qual se primava pelo Capital produtivo, por uma taxa de lucro segura, pela coordenação econômica do Estado, pelo planejamento regional e pela produção em massa.

Algo bem diferente do que acontece hoje, onde predomina o Capital financeiro, o investimento volátil e inseguro, a ausência de coordenação do Estado e a livre implementação das estratégias das grandes firmas globais. Vive-se atualmente o período das redes informacionais, da telefonia, da internet, da produção flexível e globalizada. Nesse novo período histórico, portanto, avultam-se outras categorias como Rede e Lugar. A Rede representa as articulações entre os diferentes lugares, as constantes trocas financeiras e o transito de pessoas e informações, sendo elas constituídas por nós e ligações que criam uma trama. Os nós podem significar as metrópoles globais, centros de comando da economia, cujas relações entre si constituem um arranjo, um sistema mundial.

O Lugar, por sua vez, é a categoria que exprime a contradição. Como afirma Santos (2006), nos diferentes lugares é que se realiza a globalização e, ao mesmo tempo, frequentemente insurgem os projetos de sociedade que buscam alargar as fronteiras do possível. Neste sentido, o Lugar é o ponto de intersecção entre "verticalidades" e "horizontalidades". O Lugar é também o espaço vivido definido pela relação de pertencimento, conforme assevera Tuan (1980). Rede e Lugar, portanto, expressam como nenhuma outra categoria, a dinâmica e os conflitos do mundo contemporâneo, sendo extremamente úteis na sua compreensão. Por isso mesmo, tais categorias vêm sendo largamente utilizadas pelos geógrafos, firmando cada vez a importância da Geografia no mundo.

\section{UM ENSINO DE GEOGRAFIA PARA O SÉCULO XXI}

Além da necessidade de um novo olhar, a Geografia requer também um novo modelo de ensino que permita compreender ativamente o mundo. Pelo menos desde a década de 1980 o papel dos geógrafos e do professor de Geografia tem sido redimensionado, em respaldo a todo o processo de renovação epistemológica desta disciplina. Há uma crescente percepção de que o trabalho dos geógrafos, em especial o dos geógrafos advindos de países em desenvolvimento, deve ser, cada vez mais, o de denunciador das injustiças sociais, seja em suas atividades de pesquisa ou de ensino (SANTOS, 1978). Contudo, nem sempre foi esse o papel dos geógrafos e dos professores de Geografia. Como se sabe, a geografia surgiu na esteira da construção dos Estados nacionais, sob um caráter notadamente chauvinista e vinculado à projetos imperialistas. Ipso facto, a Geografia que se ensinava nas escolas sempre esteve vinculada a um projeto 
ideológico de construção do nacionalismo e de dominação territorial, como bem observou Lacoste (2012). Este mesmo autor afirmou que a Geografia consistia, até aquele momento, em um conjunto de saberes dos espaços físicos e sociais que foi criado no quadro das funções do aparelho de Estado para o controle dos homens que povoam seu território e para a guerra. Neste sentido, ele distinguiu duas principais subdivisões dessa disciplina: a Geografia dos Estados maiores e a Geografia dos professores. A primeira dizia respeito ao conjunto sincrético de conhecimentos sobre a superfície terrestre que eram frequentemente utilizados por uma minoria de dirigentes como instrumento de poder. A segunda correspondia ao discurso ideológico a partir do qual era edificado o sentimento de nacionalismo e, ao mesmo tempo, dissimulado o caráter geoestratégico dos conhecimentos a respeito do espaço.

Portanto, a Geografia moderna, inserida no ensino escolar a partir do século XX, surgiu sob esse viés ideológico, com íntimas relações com a reorganização político-espacial que deu lugar ao chamado Estado-nação. Na verdade, os próprios sistemas escolares surgiram na Europa do século XIX com este propósito, isto é, o de locupletar os interesses capitalistas de socializar as massas, adaptar as pessoas a um mercado de trabalho em construção, bem como inculcar uma ideologia nacionalista necessária àquele momento histórico de industrialização e competição dos mercados. De todas as disciplinas, a Geografia sempre foi aquela com o maior ranço racionalizador e de memorização. Daí, portanto, os conhecimentos apresentados por ela sempre tiveram por base aquilo que é determinado pela razão científica, sufocando a imaginação e as emoções e, até mesmo, omitindo a complexidade do real. A escola, de uma maneira geral, ainda tende a lidar preferencialmente com o que a ciência moderna tem determinado enquanto verdade, fato esse que frequentemente leva os educadores a responder com descrédito os saberes provenientes da experiência dos alunos. Isso tudo, por sua vez, torna a escola e, especialmente, o ensino de Geografia, extremamente autoritários.

Tradicionalmente, e em função de sua histórica orientação ao positivismo, a Geografia observa as sociedades e seus territórios segundo um mesmo conjunto de variáveis, independente das diferenças histórico-concretas. Neste sentido, tanto o Egito Antigo, como Cuba, o Brasil ou os Estados Unidos da América (EUA) são estudados a partir dos dados de sua Natureza, de sua Demografia e de sua Economia. Trata-se, conforme esclarece Moreira (2011), da Geografia do NHE (Natureza - Homem - Economia), derivação histórica da moderna "geografia da civilização" de Ratzel e La Blache. A concepção da natureza na tríade NHE restringe-se a esfera do inorgânico, fragmentário e físico-matemático, do entorno de nossa experiência sensível. 0 homem é visto como dado demográfico que apenas está sobre o espaço, estando apartado da natureza. E a economia, por fim, amarra a estrutura lógica do NHE, transformando a natureza em recursos e o homem em força de trabalho e mercado consumidor. 
Poucos livros e compêndios didáticos de Geografia conseguem de fato fugir da supracitada lógica. Essa estrutura de ensino, existente desde a inserção dessa disciplina nos sistemas escolares, foi a responsável pela transformação da Geografia em uma disciplina essencialmente enciclopédica, tornando-a também enfadonha e, em muitos casos, inútil. É por isso que, no transcurso do século XX, a Geografia chegou a ser abolida em alguns países, como nos EUA. No Brasil, durante a Ditadura Militar, ela foi fragmentada e fundida à História, formando os "Estudos Sociais". Hoje, entretanto, em função do próprio processo de renovação da Geografia, essa disciplina vem ganhando um novo status. Na verdade, conforme dito, há um renovado interesse pela Geografia, em grande parte proporcionado pela Globalização que, direta ou indiretamente, tem exigido das pessoas um razoável conhecimento do mundo, bem como senso crítico, respeito às diferenças culturais e responsabilidade socioambiental. A problemática ambiental, diga-se de passagem, tem ganhado relevo a cada dia, sobretudo no que tange aos propósitos e limites do progresso e do desenvolvimento econômico. A Geografia, portanto, tem sido solicitada a dar respostas a esses e muitos outros dilemas da contemporaneidade.

A renovação epistemológica da Geografia, por sua vez, trouxe importantes aportes para o necessário e ainda inconcluso processo de renovação das práticas docentes. A chamada Geografia Crítica, isto é, aquela organizada sob os pressupostos do materialismo-histórico, marcante no Brasil a partir da década de 1980, inseriu importantes reflexões de natureza teórica no que concerne a qualidade e ao conteúdo de classe do ensino. Destaque para São Paulo que, no Brasil, foi o primeiro Estado a formular temáticas de cunho crítico e a inseri-las no currículo (com a contribuição decisiva do Prof. Ariovaldo Umbelino de Oliveira, diga-se de passagem). Depois, a chamada Geografia Humanística, ou seja, aquela orientada segundo os pressupostos da fenomenologia e de uma miscelânea de outras correntes filosóficas, introduziu temas como pertencimento e identidade.

A contribuição dessas duas vertentes ao ensino de Geografia foi incorporada nos Parâmetros Curriculares Nacionais (PCNs) que, mesmo com seus inegáveis problemas teóricometodológicos, passaram a incentivar os professores a adotar uma postura crítica, que leva em consideração a compreensão do espaço, e não apenas a memorização de suas diferentes feições. Os PCNs também sugerem a consideração dos laços afetivos das pessoas com o lugar que habitam, bem como as relações socioculturais dos diferentes povos com a paisagem. Neste sentido, o tratamento de conceitos como o de Paisagem, Lugar e Território são recomendados desde as séries iniciais. A íntima relação do lugar com os processos hegemônicos globais, por sua vez, induz os professores a considerarem também a Escala, as Técnicas e as Redes.

Entretanto, as recomendações dos PCNs ainda não se mostraram suficientes ao indispensável processo de reformulação do ensino da Geografia, posto que muitos professores não dominam claramente a necessária postura do "educador do século XXI". Como diria 
Vesentini (2009), é preciso vislumbrar uma Geografia para o período da terceira revolução industrial, ou revolução técnico-científica. Enquanto a escola do século XX apoiava-se no sistema escolar profissionalizante, que preparava o aluno para o mercado de trabalho, a escola do século XXI exige do aluno o "aprender a aprender", a construção autônoma de competências e habilidade, bem como uma "aprendizagem cidadã", conforme afirmou Morin (2009). 0 professor de Geografia do século XXI, por sua vez, não deve simplesmente ensinar, mas ajudar o aluno a conhecer autonomamente o mundo e a desenvolver suas potencialidades. Ele deve criar as condições para o desenvolvimento do que Lacoste (2012) chamou de "raciocínio geográfico", isto é, de um conhecimento do mundo pela via das categorias geográficas e cujas escalas local e global sejam devidamente consideradas.

Os avanços da revolução técnico-científica e a globalização exigem não apenas uma escola voltada a desenvolver a inteligência, mas o senso crítico e a iniciativa para discutir e buscar soluções para os grandes problemas globais que, por sua vez, são sempre sentidos e vividos na escala local. Para a Geografia, fica a lição do ensino contextualizado, que visa identificar na escala local os problemas ocasionados pelos processos hegemônicos globais, incentivar os alunos a encontrarem soluções. 0 professor de Geografia deve orientar, pela via da interação dialógica e da utilização das categorias geográficas, a construção ativa dessas soluções. Ademais, cabe registrar que educar é "construir significados". O conhecimento que fica e contribui qualitativamente ao desenvolvimento dos alunos é aquele que possui um significado para sua vida e para sua comunidade. É a partir de processos de "significação", constituídos com base na realidade do aluno, que o mesmo adquire a capacidade de "pensar o espaço para nele se organizar", como diria Lacoste (2012).

Por fim, vale ressaltar o papel que vem ganhando as geotecnologias enquanto linguagem da Geografia e enquanto recurso pedagógico para o ensino. Sabe-se que os Sistemas de Informação Geográficas (SIGs) foram criados como artifício da Geografia pragmática (teoréticoquantitativa), que produzia saberes essenciais às funções do aparelho do Estado. Os SIGs, portanto, servem precipuamente às estratégias dos Estados e das grandes firmas globais. Mas não se deve tomar isso de maneira definitiva, pois os SIGs também podem servir à denúncia das injustiças e à emancipação humana, a exemplo das inúmeras cartografias sociais não-cartesianas hoje construídas aos montes junto às comunidades tradicionais e povos subalternos. Um ensino de Geografia renovado e crítico é aquele que não menospreza as possibilidades hoje oferecidas pelos sistemas técnicos, mas subverte sua utilidade originária, pois entende as contradições da sociedade capitalista e sabe que delas podem insurgir projetos que visam alargar as fronteiras do possível, rumo ao novo. 


\section{CONSIDERAÇÕES FINAIS - O NECESSÁRIO CASAMENTO ENTRE O "NOVO OLHAR” E O “NOVO ENSINO”}

Tem se tornado cada vez mais premente o uso, na sala de aula, das categorias que marcam a nova visão de mundo inaugurada pela Geografia. Além disso, o professor não deve abdicar da necessidade de atualização e de uso das novas tecnologias, bem como de práticas que promovam um conhecimento contextualizado. Isso implica em assumir uma postura nova, aquela requerida pelo educador no século XXI, que seja a um só tempo flexível e arrojada. 0 professor de Geografia do século XXI deve saber construir significados e, ao mesmo tempo, ensinar a interpretar um mundo globalizado e organizado em rede.

A inserção das categorias Lugar e Rede nos conteúdos didático tem acontecido de forma muito tímida, dado o peso que ainda exerce a tradição que focaliza o olhar geográfico na Região. O professor de Geografia poucas vezes é estimulado a romper com aquilo que prescreve a tradição da pesquisa e do ensino, sendo muitas vezes forçado a replicar uma abordagem tradicional, fundada na Geografia do NHE, da memorização e dos saberes ligados ao Estadonação. Assim, o casamento entre o novo olhar geográfico sobre o mundo e o novo modelo de educação para o século XXI permanece sendo um desafio. Trata-se, contudo, de um desafio que precisa ser enfrentado e superado por todos os professores através de sua prática.

Uma forma de enfrentamento e que aponta para o referido casamento tem sido a abordagem da relação local-global. Como se sabe, a Geografia é a disciplina que permite o conhecimento do mundo, em um processo que inicia a partir do estudo do lugar. A criança ou o adolescente constrói o conceito de Lugar em contato direto com sua realidade objetiva, por meio de uma aprendizagem significativa (CALLAI, CAVALCANTI e CASTELLAR, 2012). Essa aprendizagem é construída a partir do conhecimento do entorno, da rua, do bairro, da cidade ou do trajeto entre a casa e a escola. Os alunos então percebem que não podem compreender devidamente seus lugares sem que se leve em consideração fenômenos mais abrangentes, que ocorrem em outras escalas. O lugar, obviamente, não se explica sozinho, pois requer que se considere processos mais globais. Inversamente, não é possível compreender fenômenos globais, como a própria Globalização, sem atentar para suas diferentes manifestações em escala local.

A compreensão dessa relação local-global não se dá apenas por meio de um ensino propedêutico, tradicional e preso à sala de aula. Pelo contrário, o professor deve explorar de forma ainda mais intensa os espaços não-escolares, levar os alunos aos espaços públicos e realizar trabalhos de campo. Essas práticas devem ser associadas a atividades de leitura que impliquem diferentes linguagens e formas de letramento, inclusive o digital. Neste sentido, o 
professor deve estimular e orientar o uso das tecnologias da informação (TICs) e comunicação de forma a enriquecer os trabalhos de campo com indicações de sites, vídeos, jogos, iconográfico etc. Veja-se, por exemplo, as possibilidades múltiplas e ainda pouco exploradas advindas de ferramentas gratuitas e acessíveis como o Google Earth e o Google Street View, na compreensão do lugar e dos fenômenos globais.

Outra forma de realizar o casamento entre o novo olhar geográfico e o novo modelo de educação para o século XXI é apostando no uso da cartografia, especialmente a cartografia social não-cartesiana, voltada a reconstrução de laços afetivos entre os sujeitos e seus espaços. Sua construção compartilhada, utilizando-se das TICs e em ambiente de SIGs, pode também ser fator de construção de conhecimento do lugar. Ela também ajuda a construção da chamada "alfabetização cartográfica", isto é, o conhecimento gradativo da linguagem e dos elementos dos mapas, entendendo-os como representação do espaço. A partir de então se pode, inclusive, trabalhar a questão das escalas. A possibilidade de cartografar e se apropriar idealmente do espaço representado é uma das muitas estratégias à construção da identidade, sem a qual não é possível, conforme aconselhou Lacoste (2012), "pensar o espaço para a partir dele se organizar".

A relação entre os lugares cartografados e outros no globo pode, ulteriormente, ser estabelecida através do estudo das redes. Elas podem ser compreendidas enquanto interligações entre os diferentes lugares, a teia que media a posição de cada elemento e a função que ele exerce dentro da totalidade. Pode-se começar pelas redes informacionais que os alunos utilizam para a comunicação e entretenimento, passando pelas redes de transporte e comércio. A intenção é mostrar o quanto a dinâmica socioespacial do mundo contemporâneo está atravessada pela constituição dessas redes, inclusive as atividades didáticas, as brincadeiras, os jogos e o entretenimento. As redes também pressupõem compartilhamento e produção ativa de conhecimento.

O uso de "metodologias ativas", neste sentido, pode ajudar ainda mais na compreensão de um mundo em rede. As "metodologias ativas" são o conjunto de práticas pedagógicas que estimulam o aprendizado ativo dos alunos, fazendo com que o professor seja deslocado da posição de regente da construção do conhecimento para o de facilitador e orientador. Elas se baseiam em problematizações, utilizando-se questões da vida real, sob o fito de motivar os alunos e construir junto com eles a solução desses problemas (BERBEL, 2011). Essa postura, por fim, exige dos professores muita coragem, no sentido de fazer frente à tradicional estrutura pedagógica hoje hegemônica nas escolas.

São esses, portanto, os desafios do ensino de Geografia: avançar na consolidação de um novo olhar geográfico sobre o mundo, onde as categorias Lugar e Rede estejam presentes; Renovar o discurso pedagógico, de forma a acolher a mudança, os saberes e o protagonismo discentes; Retirar a Geografia das funções do Estado e reposiciona-la no sentido de construção 
de um mundo mais justo; e fazer uso de metodologias ativas, capazes de reinventar a tradicional relação professor-aluno ainda hoje existente nas escolas.

\section{REFERÊNCIAS}

BERBEL, N. A. N. As metodologias ativas e a promoção da autonomia de estudantes. Semina: Ciências Sociais e Humanas, Londrina, v. 32, n. 1, p. 25-40, 2011.

CALLAI, H. C; CAVALCANTI, L. S; CASTELLAR, S. M. V. O estudo do lugar nos anos iniciais do ensino fundamental. Terra Livre, São Paulo, v. 1, n. 38, p. 79-98, 2012.

HARVEY, D. A produção capitalista do espaço. 2.ed. São Paulo: Annablume, 2006.

LACOSTE, Y. A geografia - isso serve, em primeiro lugar, para fazer a guerra. 19.ed. Campinas: Papirus, 2012.

MOREIRA, R. Para onde vai o pensamento geográfico? Por uma epistemologia crítica. 2.ed. São Paulo: Contexto, 2011.

MORIN, E. A cabeça bem-feita: repensar a reforma, reformar o pensamento. 16.ed. Rio de Janeiro: Bertrand Brasil, 2009.

SANTOS, Milton. O trabalho do geógrafo no terceiro mundo. São Paulo: Hucitec, 1978.
Por uma geografia nova: da crítica da geografia a uma geografia crítica. 6.ed. São Paulo: Ed. USP, 2004.

A natureza do espaço: técnica e tempo, razão e emoção. 4.ed. São Paulo: Ed. USP, 2006.

Metamorfoses do espaço habitado: fundamentos teóricos e metodológicos da geografia. 6.ed. São Paulo: Ed. USP, 2014.

TUAN, Yi-Fu. Topofilia: um estudo da percepção, atitudes e valores do meio ambiente. São Paulo: DIFEL, 1980.

VESENTINI, J. W. Repensando a Geografia escolar no século XXI. São Paulo: Plêiade, 2009.

WALLERSTEIN, I. $O$ sistema mundial moderno. Vol. II: o mercantilismo e a consolidação da economia-mundo europeia, 1600-1750. Porto: Ed. Afrontamentos, 1974 